\title{
Streptococcus mutans adhesion and releasing of metallic ions in dental alloys
}

\author{
Adriana Cristina Zavanelli ${ }^{1}$, Ricardo Alexandre Zavanelli ${ }^{2}$, José Vitor Quinelli Mazaro ${ }^{1}$, \\ Rosse Mary Falcón-Antenucci ${ }^{1}$
}

\author{
${ }^{1}$ Universidade Estadual Paulista - UNESP, Araçatuba Dental School, Department of Dental Materials and Prosthodontics, Araçatuba, SP, Brazil \\ ²Universidade Federal de Goiás - UFG, Dental School, Department of Oral Rehabilitation, Goiania, GO, Brazil
}

Received for publication: December 12, 2014 Accepted: March 06, 2015

Correspondence to: Adriana Cristina Zavanelli. Rua José Bonifácio, 1193 - Vila Mendonça CEP 16015-050 Araçatuba, São Paulo, Brasil Phone/Fax: + 5518 3636-3246/3636-3245 E-mail: zavanelliac@foa.unesp.br

\begin{abstract}
Aim: To evaluate the adherence of Streptococcus mutans to the surface of the amalgam and copper/aluminum alloy samples and also evaluate the release of metallic ions. Methods: The prepared medium was changed every $72 \mathrm{~h}$ and analyzed by atomic absorption spectrophotometer. Samples were removed from the prepared medium at 15, 30, 48 and 60 days. Results: The result shows that ions released were statistically different among all groups, and so were both biofilm and pits formation and the corrosion induced by the S. mutans in both types of samples. SEM observation of the samples immersed in the prepared medium with $S$. mutans showed adherence of microorganisms on the whole surface, in all groups. Conclusions: The S. mutans adhere to both amalgam and copper/aluminum alloy causing corrosion of those restorations. $S$. mutans produced a greater ions release in Cu/Al alloy; in amalgam, the ions release was not influenced by exposure to $S$. mutans.
\end{abstract}

Keywords: dental alloys; corrosion; ions.

\section{Introduction}

Biocorrosion in dentistry is the classic electrochemical corrosion induced by the biofilm ${ }^{1}$, which is a complex aggregation of microorganisms growing on a solid substrate ${ }^{2}$. Dental biofilm also known as dental plaque is usually disastrous. It colonizes and also contaminates not only dental surfaces but also restorations, metallic surfaces of prostheses and implants ${ }^{3-5}$, causing corrosion in pits, in a similar way as demineralized areas and decalcified cavities on tooth enamel.

Although metal-free restorations are more popular nowadays, metal restorations such as amalgam and copper/aluminum alloy are still being used widely at universities, national health services and some practices all over the world ${ }^{6-8}$. Copper/aluminum alloy and amalgam restorations still face the problem of corrosion resulting in dissatisfied patients regarding the aesthetics and also in the longevity of those restorations. Doubts still remain regarding the deleterious effects on the properties of the metallic surfaces of these alloys and their resistance to corrosion ${ }^{9-10}$. It is known that restoring materials should be resistant to corrosion to avoid biological effects caused by it and also to avoid jeopardy to esthetics $\mathrm{s}^{3,10-12}$.

However, in oral environment, these restorations are exposed to certain conditions directly related to ions release, such as $\mathrm{pH}$ reduction ${ }^{13}$ caused by Streptococcus mutans (S. mutans) after liquids and food intake ${ }^{14}$. The exposure of alloys to $\mathrm{pH}$ reduction intensifies metallic ions bleaching to tissues of surrounding oral mucosa $a^{10,14}$ and more pronounced in nickel alloys ${ }^{10,13-14}$.

According to Wataha et al. ${ }^{15}$ the metallic ions released from alloys can be 
toxic, cause inflammatory, allergenic and mutagenic reactions and can also irritate adjacent tissues.

However, the toxicity of metal-ceramic alloys depends on quantity and quality of the metallic ions released, possible synergistic or antagonist effects, and the time they remain in contact with organic tissues ${ }^{9,16-17}$.

The challenge now is to focus on this association in trying to prevent the colonization by the microorganisms and consequent corrosion. Hence, the aim of this in vitro study was to evaluate the adherence of $S$. mutans to the surface of the amalgam and copper/aluminum alloy samples and also the release of metallic ions such as copper, nickel, iron, zinc, silver, manganese, tin, aluminum and mercury on those samples when colonized by $S$. mutans.

\section{Material and methods}

\section{Sample preparation}

Amalgam Velvalloy samples (S. S. White S.A., Rio de Janeiro, RJ, Brazil) were prepared in accordance to the manufacturer's recommendations, triturated in the Silamat amalgamator (Silamat S6, Ivoclar Vivadent Inc., Amherst, NY, USA) and hand-condensed into a circular stainless steel matrix $(12 \mathrm{~mm} \times 3 \mathrm{~mm})$. Excesses were removed and burnished $5 \mathrm{~min}$ after condensation. After $25 \mathrm{~min}$, samples were removed and stored in oven at $37{ }^{\circ} \mathrm{C}$ with $100 \%$ relative humidity for $24 \mathrm{~h}$.

Four samples were produced for each studied material. Two samples were prepared for the observation of biofilm formation and the other two for the observation of pit formation. They were then divided into the following groups: Group I - burnished, sterilized in ethylene oxide gas camera (SERCON - MP 3000 HG, São Paulo, SP, Brazil) and immersed in the prepared medium with $S$. mutans; Group II - burnished, sterilized and immersed in the prepared medium without $S$. mutans; Group III - metallographic polishing, sterilized and immersed in the prepared medium with S. mutans; and Group IV - metallographic polishing, sterilized and immersed in the prepared medium without S. mutans.

Copper/aluminum alloy samples (Duracast MS, São Paulo, SP, Brazil) were obtained by the lost wax technique using the same matrix mentioned above. They were divided into the following groups: Group V - polished with abrasive roads, sterilized and immersed in the prepared medium with S. mutans; Group VI - polished with abrasive roads, sterilized and immersed in the prepared medium without S. mutans; Group VII - metallographic polishing, sterilized and immersed in the prepared medium with S. mutans; and Group VIII metallographic polishing, sterilized and immersed in the prepared medium without $S$. mutans.

\section{Induction of biocorrosion}

Samples were aseptically immersed in polystyrene conical tubes (Falcon - $50.0 \mathrm{~mL}$ ) containing $15.0 \mathrm{~mL}$ of prepared medium and MiLi-Q water (Millipore, Billerica, MA, USA), in accordance to the manufacturer's specifications. The prepared medium used was the Mueller-Hinton Broth (Difco
Laboratories Inc, Detroit, MI, USA - lot 27006) with 5.0\% sucrose (Reagen lot 961038) and 200 ì (10 microorganisms/ $\mathrm{mL)}$ S. mutans. The control samples were immersed in the same prepared medium without $S$. mutans.

Samples were then autoclaved for $15 \mathrm{~min}$ at $121{ }^{\circ} \mathrm{C}$. Tubes were incubated at $37{ }^{\circ} \mathrm{C}$, in the orbital agitator (Marconi, Piracicaba, SP, Brazil) with constant agitation of $100 \mathrm{rpm}$ for 60 days. The prepared medium was changed every $72 \mathrm{~h}$, for 60 days and reserved for analysis in the atomic absorption spectrophotometer (AAS) (Shimadzu Corporation, Kyoto, Japan) to detect the metallic ions release. All the samples were removed from prepared medium on the $15^{\text {th }}$, $30^{\text {th }}, 48^{\text {th }}$ and $60^{\text {th }}$ day, and observed by scanning electron microscopy (SEM) (JSM 5410; JEOL, Tokyo, Japan).

\section{Preparation of specimens to SEM}

Two samples were immersed in EDTA 10\% (Merck, Darmstadt, Germany) during $24 \mathrm{~h}$ to confirm the absence of biofilm. The other two samples were immersed in $\alpha$ glutaraldehyde $3.0 \%$ to confirm the presence of biofilm.

Samples were washed in sterilized distilled water and fixed in á glutaraldehyde $3.0 \%$ sodium cacodylate $0.1 \mathrm{M}$, $5^{\circ} \mathrm{C}, \mathrm{pH} 7,4$ for $12 \mathrm{~h}$. They were then postfixed in osmium tetroxide $2.0 \%, 5{ }^{\circ} \mathrm{C}$ for $4 \mathrm{~h}$, dehydrated for $15 \mathrm{~min}$ in increasing percentages of alcohol 15, 30, 50, 75, 95 and $100 \%$ and dried in the critical point dryer using $\mathrm{CO}_{2}$ (Denton vacuum - Desk II, Japan) before SEM analysis.

\section{Qualitative and quantitative analysis of metals}

A solution containing $1.0 \mathrm{~mL}$ of prepared medium and $9.0 \mathrm{~mL}$ MiLi-Q water was used for the AAS analysis. The reading of the diluted prepared medium was analyzed using standard titrisol (Merck).

The experimental model chosen in this study was described by Pizzolitto et al. ${ }^{18}$. MiLi-Q water was used to avoid metallic ions in the prepared medium or even during cleaning of the material.

\section{Results}

The result shows both biofilm and pits formation and the corrosion induced by the $S$. mutans in both amalgam and copper/aluminum samples. Metallic ion concentrations released from metal alloys are shown in Figures 1a to 1f. The highest levels of metal concentration released at 60 days: copper (approx. $80 \mu \mathrm{g} / \mathrm{mL}$ ) from Group V, zinc (approx. 4.5 $\mu \mathrm{g} / \mathrm{mL}$ ) from Groups II and I and nickel (approx. $4.5 \mu \mathrm{g} /$ $\mathrm{mL}$ ) from Group VII.

Tables 1 and 2 show the statistical analysis. Aluminum, tin and mercury were not detected in the study due to the sensibility of the method. The results for $\mathrm{Cu} / \mathrm{Al}$ alloy (Table 1) showed statistically significant difference $(p>0.05)$ between control and experimental groups. The highest values were observed in experimental group, especially in $\mathrm{Cu}$ and $\mathrm{Ni}$ ions, respectively. The results of amalgam (Table 2) ions release showed no statistically significant difference for silver 


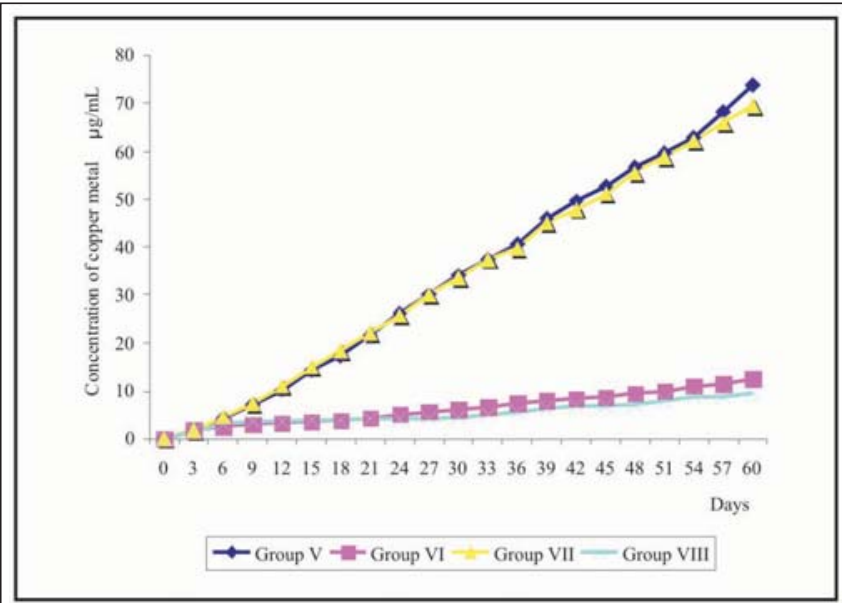

Figure 1A. Copper released from copper/aluminum alloy.

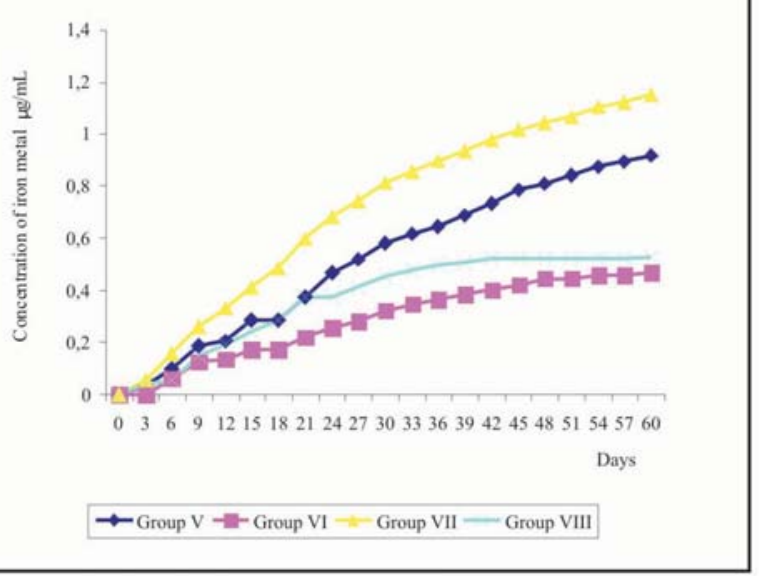

Figure 1B. Iron released from copper/aluminum alloy.

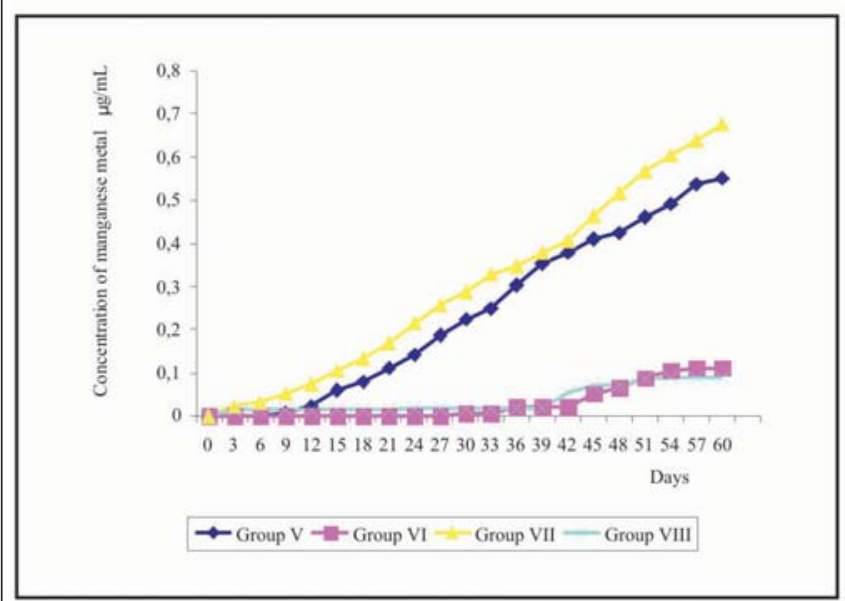

Figure 1C. Manganese released from copper/aluminum alloy.

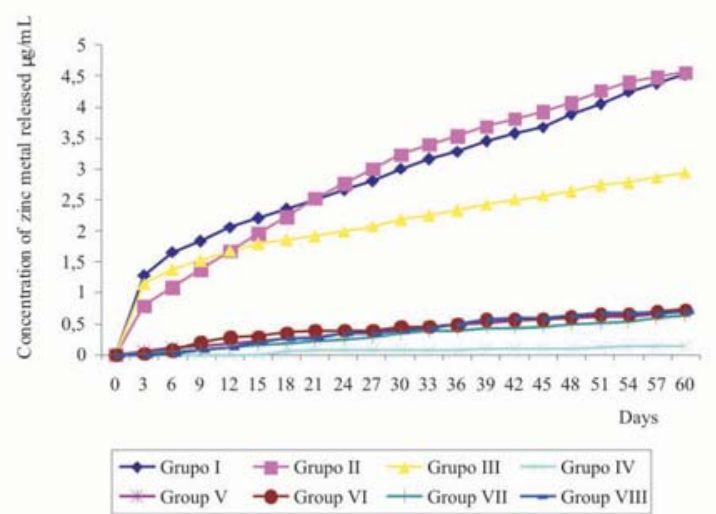

Figure 1D. Zinc released from both amalgam and copper/aluminum alloy.

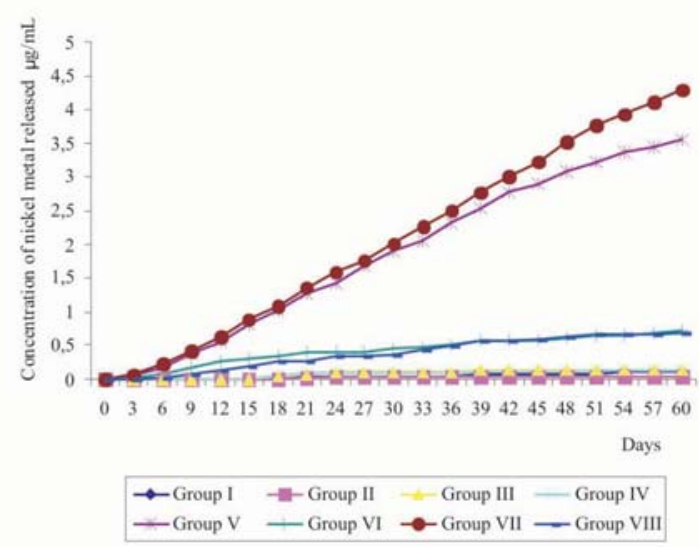

Figure 1E. Nickel released from amalgam and copper/aluminum alloy

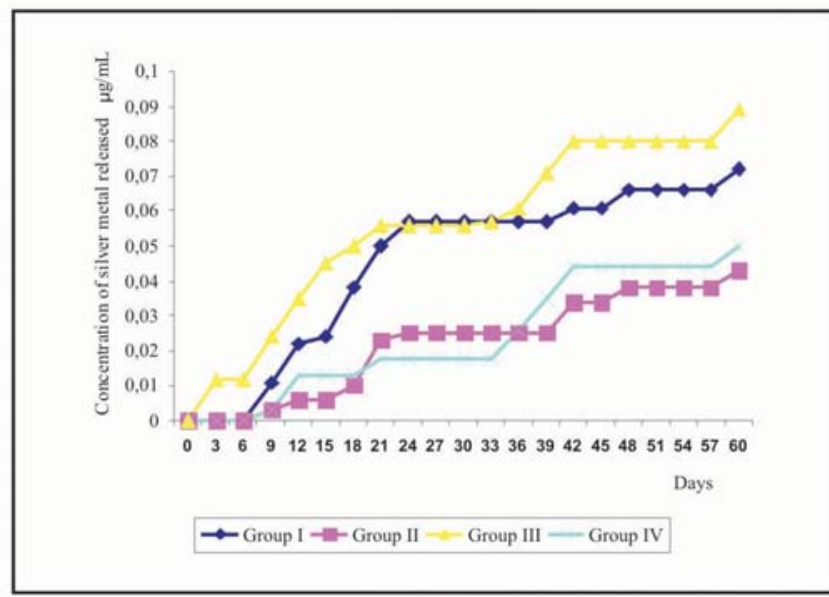

Figure 1F. Silver released from amalgam.

Fig. 1. A: Copper released from copper/aluminum alloy. Figure B: Iron released from copper/aluminum alloy. Figure C: Manganese released from copper/aluminum alloy. Figure D: Zinc released from both amalgam and copper/aluminum alloy. Figure E: Nickel released from both amalgam and copper/aluminum alloy. Figure F: Silver released from amalgam

and nickel ions. The experimental group with metallographic polishing exhibited statistically significant difference $(p>0.05)$ in comparison with the burnished experimental group.
Figures $2 \mathrm{a}$ to $2 \mathrm{f}$ show the SEM analysis of the surface of the samples immersed in prepared medium either with or without microorganism (control group). SEM observation of the samples immersed in the prepared medium with $S$. mutans 
Table 1. Results of metal ions released from culture medium with or without microorganisms $S$. mutans to copper/aluminum alloy.

\begin{tabular}{|c|c|c|c|c|c|}
\hline \multirow[b]{2}{*}{ Groups } & \multirow[b]{2}{*}{ Copper } & \multirow[b]{2}{*}{ Iron } & \multicolumn{2}{|l|}{ Metals } & \multirow[b]{2}{*}{ Nickel } \\
\hline & & & Manganese & Zinc & \\
\hline Control - abrasive roads & $0.591 B^{*}$ & $0.022 \mathrm{~B}$ & $0.005 B$ & $0.018 \mathrm{~B}$ & 0.0340 \\
\hline Control - . metallographic polishing & $0.463 B$ & $0.025 \mathrm{~B}$ & $0.004 \mathrm{~B}$ & $0.020 \mathrm{~B}$ & 0.0330 \\
\hline Experimental - abrasive roads & 3.517 A & $0.043 \mathrm{~A}$ & $0.026 \mathrm{~A}$ & $0.032 \mathrm{~A}$ & 0.169 B \\
\hline Experimental - metallographic polishing & $3.308 \mathrm{~A}$ & $0.054 \mathrm{~A}$ & $0.032 \mathrm{~A}$ & $0.030 \mathrm{~A}$ & $0.204 \mathrm{~A}$ \\
\hline
\end{tabular}

* Values followed by same letter in column to each metal were not different by Tukey's Test at $5 \%$ significance level $(p>0.05)$.

Table 2. Results of metal ions released from culture medium with or without microorganisms $S$. mutans to amalgam.

\begin{tabular}{llll}
\hline Group & Silver & Metals & Zinc \\
Control - burnished & $0.002 \mathrm{~A}^{*}$ & $0.217 \mathrm{~A}$ & $0.001 \mathrm{~A}$ \\
Control - metallographic polishing & $0,002 \mathrm{~A}$ & $0.186 \mathrm{AB}$ & $0.006 \mathrm{~A}$ \\
Experimental - burnished & $0.003 \mathrm{~A}$ & $0.215 \mathrm{~A}$ & $0.004 \mathrm{~A}$ \\
Experimental - metallographic polishing & $0.004 \mathrm{~A}$ & $0.139 \mathrm{~B}$ & $0.007 \mathrm{~A}$ \\
\hline
\end{tabular}

* Values following by same letter in column to each metal were not different by Tukey's Test at $5 \%$ significance level $(p>0.05)$.

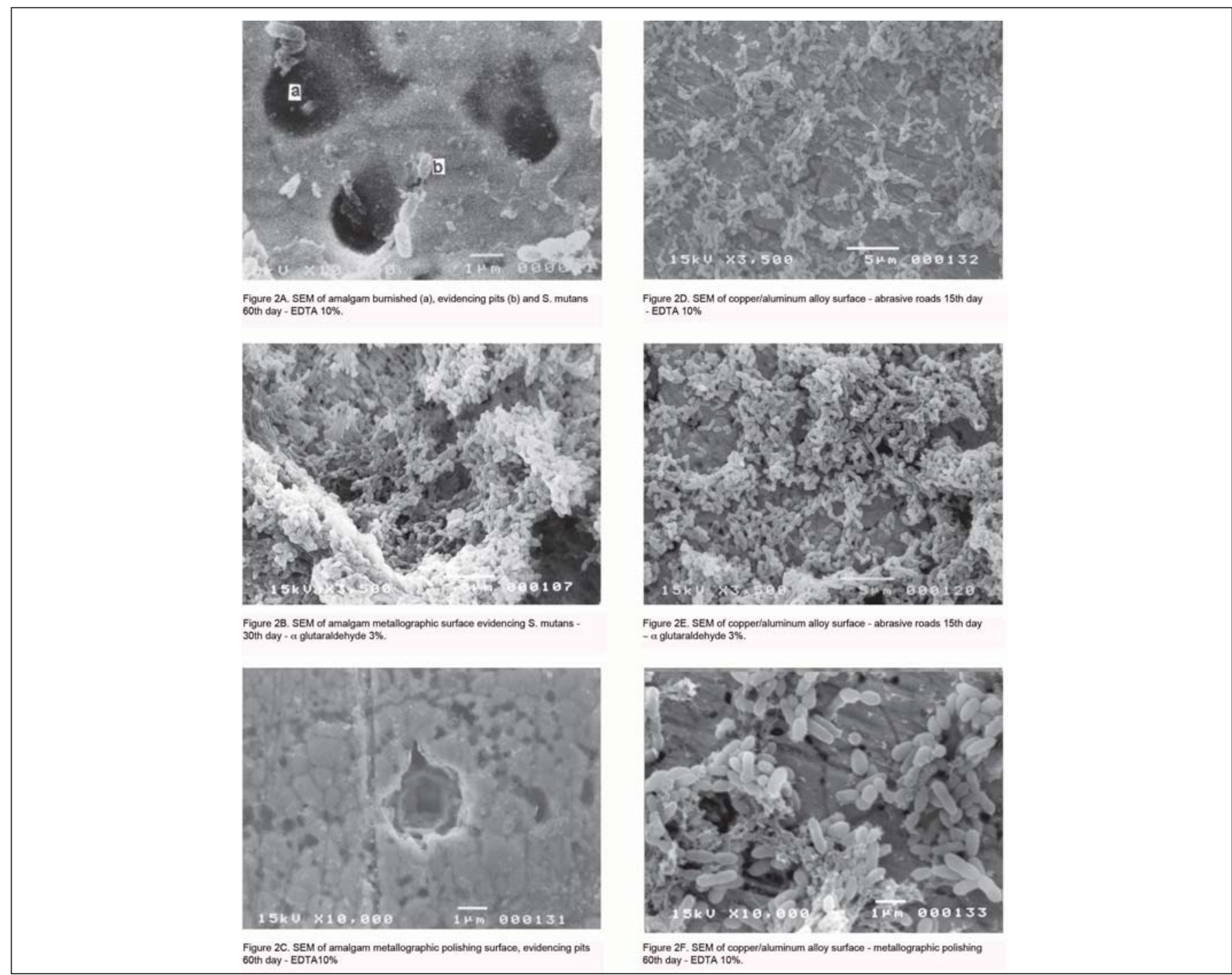

Fig. 2. A: SEM of amalgam burnished (a), evidencing pits (b) and S. mutans $60^{\text {th }}$ day - EDTA $10 \%$. B: SEM of amalgam metallographic polishing surface evidencing $S$. mutans $30^{\text {th }}$ day $-\alpha$ glutaraldehyde $3 \%$. C: SEM of amalgam metallographic polishing surface, evidencing pits $60^{\text {th }}$ day - EDTA 10\%. D: SEM of cooper/aluminum alloy surface - abrasive roads $15^{\text {th }}$ day - EDTA $10 \%$. E: SEM of copper/aluminum alloy surface - abrasive roads $15^{\text {th }}$ day $-\alpha$ glutaraldehyde $3 \%$. F: SEM of copper/aluminum alloy surface - metallographic polishing $60^{\text {th }}$ day - EDTA $10 \%$. 
showed adherence of microorganisms on the whole surface of both amalgam and copper/aluminum alloy in all groups. The release of metallic ions did not inhibit the growth of microorganisms.

\section{Discussion}

The alloy surfaces presented microorganisms' adherence and ions release was influenced by $S$. mutans, but only for $\mathrm{Cu} / \mathrm{Al}$ alloy. Despite the many studies reporting adherence of Streptococcus mutans on the surface of dental alloys $5,9-$ $10,13,15,17$, this study has proved that even release of metal ions with the samples incubated in constant agitation, there was adherence and development of the colonies. In other studies that did not use those conditions, the samples remained in the resting tube.

SEM results showed that the exposure to $S$. mutans caused microorganisms adherence on the surface of both specimens. This fact, along with the presence of gaps on the surface, makes alloys more susceptible to corrosion, and the low corrosion resistance may lead to greater ions release ${ }^{19}$. McGinley et al. ${ }^{14}$ verified $S$. mutans corrosive effect on metallic alloy disks. Corrosion is always a concern not only regarding the esthetic, but also the longevity of restorations and the possibility of causing severe allergic reaction ${ }^{20-21}$.

The atomic absorption spectrophotometer indicated that the values of ions release for $\mathrm{Cu} / \mathrm{Al}$ alloy were significantly affected by exposure to $S$. mutans. This was also observed by the study of McGinley et al. ${ }^{14}$ who assessed the influence of $S$. mutans on dental alloys' toxicity and observed that ions release significantly increased in the presence of these bacteria, as it leads to $\mathrm{pH}$ reduction. On the other hand, MutluSagesen et al. ${ }^{22}$ stated that $\mathrm{pH}$ reduction is directly related to the great ions release by dental alloys.

The $\mathrm{Cu} / \mathrm{Al}$ alloy released copper, iron, manganese, zinc and nickel ions, but copper presented the highest ions release. Benatti et al. ${ }^{23}$ showed that $\mathrm{Cu}$ and $\mathrm{Ni}$ alloys exhibit high in vitro corrosion as well as in oral cavity, mainly in areas of difficult hygiene. The ions released by amalgam were silver, zinc and nickel. However, there was no statistically significant difference between control and experimental group. Zinc ion (with $S$. mutans) presented lower release in group with metallographic polishing, perhaps due to the formation of a stable passivating layer in more polished surfaces (smoother).

Ions release can potentially alter the oral tissues' biological response in contact with dental alloys. Special attention should be given regarding the release of metallic ions in patients that presents metal allergies. The challenge now is to focus on the nature of this intimate association and try to prevent the colonization by the microorganisms and consequent corrosion.

Within the limitations of this study, the following conclusions were drawn: S. mutans adhere to both amalgam and copper/aluminum alloy causing corrosion of those restorations; $S$. mutans produced higher ions release in $\mathrm{Cu} /$ Al alloy. The amalgam ions release was not influenced by exposure to $S$. mutans.

\section{Acknowledgements}

The authors thank Heitor Panzeri and Izabel Yoko Ito (in memoriam) for their contributions to this study.

\section{References}

1. Beech IB, Sunner J. Biocorrosion: towards understanding interactions between biofilms and metals. Curr Opin Biotechnol. 2004; 15: 181-6.

2. Beech IB, Sunner JA, Hiraoka K. Microbe-surface interactions in biofouling and biocorrosion processes. Int Microbiol. 2005; 8: 157-68.

3. Garhammer P, Schmalz G, Hiller KA, Reitinger T. Metal content of biopsies adjacent to dental cast alloys. Clin Oral Invest. 2003; 7: 92-7.

4. Laurent F, Grosgogeat B, Reclaru L, Dalard F, Lissac M. Comparison of corrosion behaviour in presence of oral bacteria. Biomaterials. 2001; 22: 2273-82.

5. Elshahawy W, Watanabe I, Koike M. Elemental ion release from four different fixed prosthodontic materials. Dent Mat. 2009; 25: 976-81.

6. Leinfelder KF. An evaluation of casting alloys used for restorative procedures. JAm Dent Assoc. 1997; 128: 37-45.

7. Wataha JC, Messer RL. Casting alloys. Dent Clin North Am. 2004; 48: 499-512.

8. Darwell BW. Effect of corrosion on the strength of dental silver amalgam. Dent Mat. 2012; 28: 160-7.

9. Elshahawy W, Ajlouni R, James W, Abdellatif $\mathrm{H}$, Watanabe I. Elemental ion release from fixed restorative materials into patient saliva. J Oral Rehabil. 2013; 40: 381-8.

10. Can G, Akpinar G, Aydin A. The release of elements from dental casting alloy into cell-culture medium and artificial saliva. Eur J Dent. 2007; 2: 86-90.

11. Galo R, Ribeiro RF, Rodrigues RC, Rocha LA, de Mattos Mda G. Efects of chemical composition on the corrosion of dental alloys. Braz Dent J. 2012; 23: 141-8

12. Lu Y, Chen W, Ke W, Wu S. Nickel-based (Ni-Cr and Ni-Cr-Be) alloys used in dental restorations may be a potential cause for immune-mediated hypersensitivity. Med Hypotheses. 2009; 73: 716-7.

13. Wataha JC, Lockwood PE, Khajotia SS, Turner R. Effect of pH on element release from dental casting alloys. J Prosthet Dent. 1998; 80: 691-8.

14. McGinley EL, Dowling AH, Moran GP, Fleming GJP. Influence of S. mutans on base-metal dental casting alloy toxicity. J Dent Res. 2013; 92: 92-7.

15. Wataha JC, Malcolm CT, Hanks CT. Correlation between cytotoxicity and the elements released by dental casting alloys. Int J Prosthod. 1995; 8: 9-14.

16. Wataha JC. Biocompatibility of dental casting alloys: a review. J Prosthet Dent. 2000; 83: 223-34.

17. Oyar P, Can G, Atakol O. Effects of environment on the release of $\mathrm{Ni}, \mathrm{Cr}, \mathrm{Fe}$, and Co from new and recast Ni-Cr alloy. JProsthet Dent. 2013; 112: 64-9.

18. Pizzolitto EL, Lochagin N, Bernardi ACA, Ito IYS, Guastaldi AC. Microbial corrosion of biomaterials. J Dent Res. 1998; 35: 348.

19. Wylie CM, Shelton RM, Fleming GJP, Davenport AJ. Corrosion of nickelbased dental casting alloys. Dent Mat. 2007; 23: 714-23.

20. Hansen PA, West LA. Allergic reaction following insertion of a Pd-Cu-Au fixed partial denture: a clinical report. J Prosthodont. 1997; 6: 144-8.

21. Gokcen-Rohlig B, Saruhanoglu A, Cifter ED, Evlioglu G. Applicability of zirconia dental prostheses for metal allergy patients. Int J Prosthodont. 2010; 23: 562-5.

22. Mutlu-Sagesen L, Ergun G, Karabulut E. Ion release from metal-ceramic alloys in three different media. Dent Mat J. 2011; 30: 598-610.

23. Benatti OFM, Miranda WG, Muench A. In vitro and in vivo corrosion evaluation of nickel-chromium-and copper-aluminum-based alloys. J Prosthet Dent. 2000; 84: 360-3. 